\title{
Emotional Dynamics of Right- and Left-Wing Political Populism
}

\author{
Salmela, Mikko Erkki Matias
}

2018-09-24

Salmela , M E M \& von Scheve , C 2018 , ' Emotional Dynamics of Right- and Left-Wing

Political Populism ' , Humanity \& Society , vol. 42 , no. 4 , pp. 434-454 . https://doi.org/10.1177/0160597618802521

http://hdl.handle.net/10138/323996

https://doi.org/10.1177/0160597618802521

cc_by_nc_nd

acceptedVersion

Downloaded from Helda, University of Helsinki institutional repository.

This is an electronic reprint of the original article.

This reprint may differ from the original in pagination and typographic detail.

Please cite the original version. 
Emotional dynamics of right- and left-wing political populism

Mikko Salmela and Christian von Scheve

To appear in a special issue "Emotional Dynamics of Backlash Politics", edited by Joel Busher, Philip Giurlando, and Gavin B. Sullivan, Humanity \& Society, 42(4), 2018

\begin{abstract}
Emotions are prevalent in the rhetoric of populist politicians and among their electorate. We argue that partially dissimilar emotional processes may be driving right- and left-wing populism. Existing research has associated populism with fear and insecurities experienced in contemporary societies on the one hand, and with anger, resentment, and hatred on the other. Yet, there are significant differences in the targets of right- and left-wing resentment: a political and economic establishment deemed responsible for austerity politics (left), and political and cultural elites accused of favoring ethnic, religious, and sexual outgroups at the expense of the neglected ingroup (right). Referring to partially different emotional opportunity structures and distinct political strategies at exploiting these structures, we suggest that right-wing populism is characterized by repressed shame that transforms fear and insecurity into anger, resentment, and hatred against perceived "enemies" of the precarious self. Left-wing populism, in turn, associates more with acknowledged shame that allows individuals to self-identify as aggrieved and humiliated by neoliberal policies and their advocates. The latter type of shame holds emancipatory potential as it allows individuals to
\end{abstract}


establish bonds with others who feel the same, whereas repressors remain in their shame or seek bonds from repression-mediated defensive anger and hatred.

\section{INTRODUCTION}

Populist parties and political movements have risen or become stronger all over Europe in the aftermath of the EU's financial crisis, the politics of austerity, and the increasing number of refugees and immigrants. This development has been similar in countries like Greece and Spain where radical cuts to welfare transfers and services were implemented as a precondition for bailout loans, but also in countries such as Finland, France, Germany, and the Netherlands that contributed to the bailout while struggling with the crisis themselves. Together, the downturn that was initiated by the crisis and its management created a reservoir of discontent, despair, and anger amongst many Europeans. These collective emotions have fueled protests against governments held responsible for unjustified and unpopular politics (e.g. Gerbaudo 2017).

Our aim in this article is to make a contribution to explaining the emergence and success of different types of populism in structurally and socially similar conditions of modernization, globalization, and economic deregulation that are widely perceived as crisis-laden (e.g. Brubaker 2017). Given that these changes have affected individuals similarly across Europe and other parts of the world, why have these processes predominantly harbored support for the political right rather than the left that has traditionally benefited from wide-ranging social dissatisfaction? While the recent rise of populism has been global (see Moffitt 2016), 
we limit our discussion to electorally successful and well-researched cases of right- and leftwing populism in Europe and North America.

Right-wing populist parties have garnered significant support in Western, Eastern, Central, and Northern Europe as well as in the United States. In contrast, left-wing populism has advanced in some, mainly Southern European countries such as Greece and Spain (countries most severely hit by the financial crisis and policies designed to its remedy), although the success of old-school socialists Jeremy Corbyn in the United Kingdom and Bernie Sanders in the United States who target economic elites in their anti-establishment politics can be interpreted as left-wing populist as well. Even so, the preponderance of right-wing populism on both sides of the Atlantic suggests that we may take it as a dominant type of populism in contemporary Western societies, while successful cases of left-wing populism appear as exceptions that need different type(s) of explanation. ${ }^{1}$

In this article, we aim to develop theoretical propositions, based on existing empirical research in the social sciences, that may contribute to explaining why in the aftermath of the recent crises, right-wing populist parties have received considerably more support from the electorate than left-wing populist parties. Our approach builds on previous work (Salmela \& von Scheve 2017) in which we have identified two social psychological mechanisms that drive support for the populist right ${ }^{2}$. The first mechanism is linked to feelings of ressentiment and explains how negative emotions (in particular fear and

\footnotetext{
${ }^{1}$ We focus on clear-cut and well-researched cases of left-wing populism such as Podemos (Spain) and SYRIZA (Greece). The Italian M5S is more like a synthesis of right- and left-wing populism (e.g. Ivaldi et al. 2017), and there is no research on the new left-wing populist La France Insoumise that succeeded well in 2017 French presidential elections.

${ }^{2}$ See Elster (1999) for the notion of emotional mechanism.
} 
insecurity) transform, through repressed individual shame, into anger, resentment, and hatred toward various outgroups. The second mechanism relates to the emotional distancing from social identities that inflict shame and other self-focused negative emotions, and instead promotes seeking identities that are perceived to be less crisis-afflicted and to some extent exclusive, such as nationality, ethnicity, and religion. Based on this work, we ask how these (and other) mechanisms might operate in the context of left-wing populist support and whether they can contribute to explaining cross-national differences in rightand left-wing support.

This comparative stance inevitably points to the more established differences between political parties and ideologies and can thus in principle also be extended to right- and leftwing parties more generally. However, our approach capitalizes on the rise of "new" populist parties because they can be understood as epitomes of processes of emotionalization and an affective polarization of politics (lyengar et al. 2012) to which our theoretical model speaks first and foremost.

In the following, we first introduce the concept of emotional opportunity structures (EOS) (Ruiz-Junco 2013), a form of political opportunity structures (Tilly 1978; Meyer 2004), that have been invoked in accounting for historical contingencies on which the attractiveness and mobilization potential of social movements may hinge. In a second step, we briefly review some of the existing research on emotions in political populism and suggest that EOS are essential in rendering populist politics and rhetoric more or less appealing, depending on the strategies of exploiting a specific EOS and on the specific cultural and historical context. In a third step, we then provide a detailed outline of ressentiment as a complex 
emotional mechanism that emerges from the overarching EOS of contemporary neoliberal capitalism. We then specify the workings of this mechanism in different national contexts and under varying EOS, emphasizing their consequences for the support and appeal of rightand left-wing populism. In particular, these differences pertain to (a) the repression versus. acknowledgment of shame, (b) different organizational cultures of right- and left-wing movements, and (c) and distinct ways of appealing to different forms of identity. Finally, we offer a conclusion and provide an outlook on future research.

\section{EMOTIONAL OPPORTUNITY STRUCTURES OF POLITICAL POPULISM}

Looking at contemporary right- and left-wing populist parties across Europe, it is not surprising that many have emerged from or made close alliances with corresponding social movements. Even where this is not the case, many of the parties are newly founded parties that, especially in their early years, but in some cases also later when they become more popular, have strong resemblances with social movement organizations. The German AfD was founded in 2013, the Polish Law and Justice in 2001, the Greek SYRIZA in 2004, and Spanish Podemos in 2014. In order to understand the success of right- and left-wing populist parties, it thus seems reasonable to also consider explanatory models from social movements research.

In this literature, opportunity structures or political opportunity structures are seen as answers to the question of how social movements emerge at a given time (Meyer 2004: 127). Going beyond established collective behavior or resource mobilization accounts, the 
concept of opportunity structures broadly refers to movements' external social and political circumstances in explaining why movements (can) emerge in the first place. In a review of the existing literature, McAdam (1996: 27) identifies four key dimensions of political opportunities: (1) openness or closure of the institutionalized political system, (2) relative stability of the elite alignments that undergird a polity, (3) presence or absence of elite allies, and (4) the state's capacity for repression. McAdam (1996) and others (e.g., Gamson \& Meyer 1996) are careful to distinguish these specifically political opportunity structures from other external constraints on or facilitators of social movements, such as structural or cultural opportunities, the latter of which, according to McAdam (1996), include inflated contradictions between ideational values and actual practices, the dramatization of a society's vulnerability or illegitimacy, or certain types of events, for instance legal decisions, pandemics, or disasters. In fact, Gamson and Meyer (1996) sort the factors contributing to political opportunity along a cultural-institutional axis (see also Polletta 2004).

Looking at the success of (newly emerged) right- and left-wing populist parties, this raises the question of which opportunity structures might have contributed to the success of these parties and how this occurred in different countries. On the one hand, certain structural and cultural opportunities have been present in many European countries to varying degrees and in different shapes due to the debt crisis since 2008 and the refugee crisis since the beginning of 2015. Although these developments present "opportunities" for political exploitation on the left and right, they do so differently in different countries. For example, most Southern European countries were more severely hit by the debt crisis than Northern and Western European countries, who instead contributed to bailout loans. Likewise, migration routes of refugees initially disproportionately affected Southern and Southeastern 
European countries, whereas in later stages Western European countries (also)

accommodated large numbers of refugees. On the other hand, there is a host of domestic political opportunities that may promote either right- or left-wing populist parties to thrive, for instance terrorist attacks, events like the sexual assaults on New Year's Eve 2015 in Cologne and other German cities, or Greek mainstream politicians requesting blame for the financial crisis be directed at the entire Greek society rather than at political and economic elites alone (Xenakis \& Cheliotis 2014), or collective memories of emancipation from communism in Central and Eastern Europe that may serve as sounding board for nationalist sentiments in these countries. Moreover, genuinely political opportunities have contributed to the rise of populist parties, for example the weakening of the Social Democrats and Liberals in Germany, or the 1993 electoral reform in Italy that contributed to Silvio Berlusconi's success (Fella \& Ruzza 2013).

Certainly, these opportunities may contribute to explaining the success of both, right- and left-wing parties, but they are not particularly convincing for explaining the rise of populist parties. Regarding this explanatory gap, we suggest that emotional opportunity structures (EOS) can add to our understanding of the differential success of right- and left-wing populist parties. Social movements research has for several years emphasized the relevance of emotions for the emergence and success of movements. Ruiz-Junco's (2013) overview of this literature summarizes the crucial role that emotions play in terms of (1) the management and regulation of emotions in and through social movements, (2) the particular framing of political issues in such a way that it creates an emotional resonance, (3) the larger emotional culture within which process of emotion regulation and emotional framing take place, and (4) emotional opportunities which present themselves when certain 
structural, institutional, and cultural arrangements either permit and foster or obstruct and render unintelligible some emotions but not others (see also Whittier 2001).

EOS, sometimes also referred to as "libidinal opportunity structures" (Goodwin 1997), can thus be conceived of, first, as specific constellations in the structural and institutional "makeup" of a society that act as reference points for the appraisal processes underlying citizens' emotions. They are the macrosocial eliciting conditions for certain emotions and at the same time may hinder the generation of other emotions. Insecurity and anxiety in a society plagued by economic downturn and unemployment are obvious examples, as would be envy and shame in a society that promotes constant social comparison. By contrast, secure employment and future prospects in a society are supposed to hinder resentment against immigrants. In existing research on populism, structural factors of this kind and the emotions triggered by them are often referred to as belonging to the "demand" side of populism (e.g., Guiso et al. 2017). The notion of EOS highlights the connection between structural conditions and changes in a society and their likely emotional consequences, which the notion of "demand" alone does not explicate. Second, EOS are constituted and maintained by social and cultural processes that render (certain) emotions more visible, desirable, and acceptable than others. Fear in a "culture of fear" (Furedi 2007) or happiness in a culture that relentlessly emphasizes positive emotions (Ahmed 2010) are good examples of distinct emotions that are enabled by specific emotional opportunities and also reflect a dominant emotional culture.

We suggest that the concept of EOS can help us understand why in certain countries leftwing rather than right-wing populist parties have been so successful and why populist 
parties rather than the more established parties have garnered this much attention and managed to mobilize voters in significant numbers. Importantly, we suppose that the existence of EOS is not linked to a specific political party or movement. Parties and movements, at least within a comparable social and cultural context, such as the nation state, generally face the same EOS. Whether they turn these structures into actual opportunities for mobilization and political support is a question of their respective strategies and rhetoric and their (distinct) ways of interpreting, framing, and conveying the meanings and implications of these structures in discursive ways. With their rhetoric, populist movements and parties can be particularly adept at tapping into new emotional opportunities that emerge in new structural conditions and from their mismatch with existing emotional cultures. We illustrate this conjecture by first outlining the general associations between populism and emotions and second by discussing how these associations may work differently for right- and left-wing populist parties.

\section{RIGHT- AND LEFT-WING POPULIST EXPLOITATION OF EOS}

Existing research on populism has focused on two clusters of negative emotions that fuel the rise of populist parties and movements, either left or right: feelings of fear associated with insecurity, powerlessness, and déclassement on the one hand, and anger, resentment, indignation, and hate on the other hand. These emotions can be understood as closely tied to social structural and cultural changes that can be conceived of as presenting specific emotional opportunity structures: fear of losing social status and established living standards, and of becoming part of a stigmatized group, such as the unemployed, have 
spread along with increased economic precariousness in contemporary societies that also encompass existential, cultural, physical, and environmental forms of uncertainty (e.g. Bauman 2001; Flecker et al. 2007; Furedi 2007; Kinnvall 2013). "Islamic terrorism" is a further source of fear that motivates support for right-wing populist parties advocating cultural protectionism and restrictions on immigration. Likewise, economic changes and increasing strains on labor with their implications for status and living standards are sources of anger and resentment in contemporary societies (Flecker et al. 2007; Rackow et al. 2012; Cramer 2016; Hochschild 2016). With individualized careers and risks, employees become more and more "entrepreneurs of the self" (Foucault 2008) who compete with each other about various resources and recognition. Accordingly, those who are perceived to avoid work or live off the work of others are held responsible for creating conditions of increased competition and become targets of anger, resentment, indignation, and hate. However, there is little understanding on how the emotions of right- and left-wing populists and their sympathisers differ from each other. We argue that the prevailing, though historically contingent, EOS within a specific political context and the ways in which they are addressed and exploited by populist parties bring about these differences.

Taking the financial and debt crises since 2008/2009 as an EOS, one straightforward difference lies in the discursive construction of different targets of emotions associated with these crises. For example, although anger and resentment are frequent emotions on both sides of the political spectrum, they tend to reflect dissimilar understandings and framings of "the people". Contemporary right-wing populists typically define "the people" in nativist and ethnic terms that excludes non-native populations such as refugees and immigrants, as well as ethnic, religious, or sexual minorities. They also devote more attention to defining 
the various outgroups than their own ingroup, as Mudde and Kaltwasser (2012) point out. In contrast, present-day left-wing populists identify "the people" as all those who have been aggrieved by neoliberal austerity politics. This understanding of "the people" is inclusionary as it emphasizes the equal rights of women, immigrants, and LGBTQ people (Stavrakakis \& Katsambekis, 2014). Likewise, for left-wing populists in Greece and Spain, the "internal elite" is the political and economic establishment responsible for implementing austerity politics, required by "the external elite": the Troika of European Commission, European Central Bank and the International Monetary Fund; as in the rhetoric of Alexis Tsipras: "external troika" vs. "internal troika" (Brubaker 2017: 364).

For right-wing populists, "the elite" refers to political and cultural elites that are accused of favoring, both economically and culturally, various outgroups at the expense of "the people" defined in nativist terms. Accordingly, right-wing populist rhetoric and discourse promote anger and resentment directed at those who have a "good life" without hard work, such as politicians and top managers on high and secure income, welfare recipients and refugees "looked after by the state", and the long-term unemployed who "avoid work", but also at groups perceived to be different from "us": ethnic, cultural, political, and sexual minorities. By contrast, left-wing discourse and rhetoric instill anger and resentment at those responsible for enforcing politics perceived to increase injustice, inequality, and precariousness, such as national governments and supranational institutions (EU, ECB, IMF). Aside from these relatively straightforward differences in the targets of anger and resentment, there are less obvious differences in the emotional dynamics of right- and left- 
wing populism on which we capitalize in the following section by linking them to shame, resentment, and ressentiment.

\section{RESENTMENT AND RESSENTIMENT}

We suggest that a critical difference in the emotional dynamics of right- and left-wing political populism concerns the different roles of resentment and ressentiment among their supporters. A prominent theory regarding the success of especially right-wing populist parties has emphasized the emotion of resentment or ressentiment (Betz 1994; Demertzis 2006; Berezin 2009). Resentment is a very general affective category under which Betz (1994) discusses (a) distrust, alienation, discontent, cynicism, pessimism, insecurity, and feelings of powerlessness; (b) anger about perceived unjust or unfair treatment; and (c) hate as an intensification and/or temporal extension of resentment. While resentment is generally understood as a long-term affective attitude a person develops in response to another's insult, injury, or offence (Strawson 1974, Meltzer and Musolf 2002), ressentiment in the technical sense - as introduced by Nietzsche and first elaborated by Scheler (1994 [1915]) - emerges from other negative emotions such as envy, malice, or spite toward another person or persons in situations where one feels impotent to act on one of these emotions. These emotions are then repressed and transformed into passive resentment, hostility, or hatred toward the other. Moreover, ressentiment involves a sense of powerlessness and self-disvalue in comparison with others. The main differences between resentment and ressentiment concern the sense of one's own powerlessness and the repression of other negative emotions that are involved in ressentiment but not in 
resentment. However, these ressentiment theories have not been eager to clarify the other negative emotions that produce and maintain experiences of individual weakness and powerlessness in the "background" of ressentiment, keeping it diffuse and wide.

Whereas we (Salmela \& von Scheve 2017) have previously focused on typical patterns of ressentiment and the distancing from precarious social identities amongst supporters of right-wing populist parties, in what follows we attempt to carve out how these mechanisms operate differently under left- and ring-wing populist rhetoric and discourse that serve as collective forms of emotion management, for instance, by identifying legitimate targets of resentment and objects of solidarity. In essence, we suggest that feelings of fear, powerlessness, insecurity, worthlessness or shame - negative emotions targeting the self fuel ressentiment amongst adherents of right-wing populist parties, whereas left-wing populist parties pursue strategies that are suited to turn these feelings into resentment without the involvement of ressentiment. In the following, we argue, firstly, that this basic difference becomes manifest, because the (discursive) repression of negative emotions, in particular of shame, is more prevalent amongst right-wing populist supporters whereas these emotions tend to be acknowledged and socially shared within the left-wing populist camp. We also suggest that these different emotion management strategies - as distinct means of exploiting an EOS - have importantly dissimilar social consequences: Repressed negative emotions about the self transform into anger, resentment, and hatred against various outgroups, whereas their acknowledgement and sharing allow their transformation into anger and indignation toward particular others perceived to be responsible for one's (unfavorable) position. Secondly, we suggest that the organizational culture and structure of right- and left-wing political parties and movements are important factors regarding the 
repression and acknowledgement of shame. Finally, we argue that the difference between repression and acknowledgement also has implications for the emotional distancing from certain social identities or their embracement.

\subsection{SHAME: REPRESSED VS. ACKNOWLEDGED AND SHARED}

We suggest that many fears and insecurities that are linked to prevailing EOS in contemporary societies contribute to producing actual or anticipated shame that - when repressed - transforms into anger and resentment toward various "enemies" of the self (see Scheff 1994; Turner 2007). Shame has been an "invisible" emotion in studies of populism because it is rarely articulated by informants and interviewees in empirical studies. Even so, we believe that it is a pivotal emotion of contemporary societies where principles of competition and market exchange have spread from the economy to all domains of life (Bauman 1998). Here, shame emerges as an emotion about actual or anticipated losses for which individuals blame themselves. Anticipatory shame, or shame-anxiety, may not be as intense as actual shame, but it resembles the latter in its unpleasant hedonic quality and negative implications for the self. This is because it signals an expected loss rather than a possible loss or social exclusion (Neckel 1991; Miceli \& Castelfranchi 2015). In general, the more domains of life in a society operate on the principles of competition and market exchange, the more chances there are for failing to live up to the constitutive values of one's salient personal and social identities, and, consequently, for shame about this actual or anticipated incapacity, and for the repression of shame. 
As argued by Scheff (1994) and Turner (2007), the repression of shame can be considered as part of a general EOS of modern (Western) societies, since shame is seen and culturally framed as a deviant, despised, and socially undesirable and therefore inexpressible emotion (as opposed to, for example, the role of shame in some East Asian societies, see Stodulka 2017). However, repressed shame does not disappear, but persists, becomes more intensive, and transforms into anger, hate, and resentment (e.g. Hoggett et al. 2013). The idea is that psychodynamic processes change both the emotion type (from shame to anger, hate, and resentment) and its intentional object (from self to other), with the purpose of protecting the vulnerable self. This mechanism is similar to Scheler's Ressentiment because the repression and transmutation of negative emotions and a shift in their intentional directedness are central to that concept as well.

Importantly, repression makes it difficult for the subject to recognize the contexts in which shame emerged. Therefore, "the structures that originally generated negative emotional arousal are frequently not the targets of external attributions" (Turner 2007: 521, original italics). Another reason for the invisibility of eliciting structures are ideologies, such as competitive individualism, that justify the unequal distribution of resources in different domains. When these ideologies are taken for granted, the contribution of social structures to the shame-producing distribution of resources remains mostly invisible. Turner remarks that once "shame is repressed, it can be manipulated by those with an interest in deflecting this anger onto chosen targets; typically this manipulation involves the symbols of one social identity and juxtaposes this identity through narratives about the evils of another social category or social identity" (Turner 2007: 521-522). 
Repressed shame therefore constitutes a social mechanism that may mediate between the EOS of contemporary societies on the one hand, and support for right-wing populist parties on the other hand. We suggest that the rhetoric of these parties is carefully crafted (a) to contribute to the repression of shame and (b) to deflect shame-induced anger and hatred away from the self and instead toward the political and cultural establishment and various Others, such as immigrants, refugees, and the long-term unemployed. This is why structural changes like globalization and economic liberalization - the actual causes of many of the events that provoke individual shame - until recently received little attention from rightwing populists, who now seek to fight globalization by protectionism. Yet, this blaming of other countries and transnational organizations allows other aspects of contemporary capitalism to get off easily, or even receive support when figureheads such as Donald Trump are voted for.

If the EOS of contemporary societies promote actual or anticipated shame across borders, why do we not see right-wing populism succeed everywhere? One structural reason for possibly dissimilar dynamics of shame is that the austerity cuts implemented in countries such as Greece and Spain were more radical and more noticeable than those in Western and Northern European countries. The fact that large segments of the population have been affected by austerity cuts in these countries has probably given rise to a common awareness, reinforced by left-wing populist slogans such as "We are the $99 \%$ ", that individual citizens cannot be blamed for losing their jobs, homes, or prospects of a secure life in consequence of cuts to salaries, pensions, and public services (della Porta 2015; Gerbaudo 2017). Protesters may thus be more likely to self-identify as aggrieved by neoliberal policies and to blame politics, politicians, and institutions perceived to be 
responsible for the situation instead of blaming themselves (Simiti 2016). In Greece, mainstream politicians wanted to blame the entire society for corruption that lead to the crisis rather than blaming those elites who primarily benefited from the corruption, thus producing anger among citizens (Xenakis \& Cheliotis 2014). In contrast, citizens in countries less affected by the financial crisis might face the consequences of neoliberal globalization and their own vulnerability in more individualized terms, which would contribute to each individual accepting more responsibility for his or her actual or anticipated losses and precarious condition. This kind of responsibility attribution is further supported by a neoliberal citizenship regime (Wacquant 2008).

In this way, the proportion of citizens in a country affected by the consequences of neoliberal politics, a corresponding public discourse, and tailored political rhetoric can be important factors influencing whether shame is either acknowledged or repressed, or whether it is felt in the first place. For if others rather than the self are blamed for demeaning and undeserved treatment, the resulting emotion would be humiliation rather than shame. Yet, even if people had felt ashamed of their situation, the rather large number of aggrieved citizens would likely have supported the public acknowledgement of this emotion rather than its privatization and repression. This is an important difference because the former type of shame holds significant emancipatory potential as it allows individuals to identify and establish bonds with others who feel the same for similar reasons. Here is Simiti's account on this process in the leftist camp of the Greek Aganaktismenoi movement:

As well as articulating opinions, the participants shared their feelings of anger, confusion and anxiety. Social interaction with even strangers was common. Since in 
the Greek context problems like poverty, unemployment and private debt were experienced by numerous and diverse social groups, they were openly discussed and debated. Thus individual experiences were stripped of any moralistic discourse, individual deficiency or failure and were transformed into shared social experience. (Simiti 2016: 41)

This sharing of experiences is likely to have contributed to the formation of a collective identity amongst protesters. This collective identity, in turn, can facilitate the transformation of individual shame into collective humiliation, anger, and indignation that would allow the aggrieved - in conjunction with a corresponding rhetoric - to blame others perceived to be responsible for their precarious situation.

Arguably, citizens may have felt humiliation, anger, and indignation instead of shame already at the outset of the crisis as they interpreted their losses and precarization along with left-wing populist narratives associating their (anticipated) losses with austerity politics and other societal changes implemented by unpopular governments. For instance, supporters of Podemos have been characterized as a group of highly skilled individuals with unfulfilled expectations "who, disappointed by the mix of economic and political crises, are targeting their anger at both the government and the mainstream opposition" (Ramiro \& Gomez 2017: 122). With some speculation, these citizens who are younger, more educated, and ideologically more diverse than the average left voter, are less likely to blame themselves for their precarious situation because they have accomplished a range of precautionary tasks to shield them from these losses. With mass unemployment amongst younger generations, these individuals may have, supported by the rhetoric of Podemos, 
experienced themselves as victims of social or intergenerational injustice or both (Gerbaudo $2013,2017)$. With both interpretations, anger and indignation at those who have changed "the rules of the game" would ensue rather than shame that targets the self.

\subsection{ORGANIZATIONAL CULTURE AND STRUCTURE}

Given that the public acknowledgment and consequent social sharing of negative emotions can be an important difference between right- and left-wing political strategy and rhetoric, we suggest - this being our second difference - that also the distinct organizational structures of the two types of populism contribute to different intensities of sharing. Recent left-wing populism in Europe has emerged or been invigorated by popular social movements with a rather horizontal, informal, open, and networked structure rather than a vertical, formal, hierarchical, and representational structure that is common to both traditional parties and informal, yet typically hierarchically structured, leader-centered right-wing populist parties (e.g. Moffitt 2016; Kioupkiolis 2016; Gerbaudo 2013, 2017). These parties prefer to emphasize their origin in or even nature as social movements, even if they typically have no such history or organizational structure. For instance, the German AfD does not originate from the far-right social movement Pegida, nor does it imitate the organizational structure of Pegida, even if the party and social movement share nationalist and antiIslamist ideals and have recently collaborated. ${ }^{3}$ The relationship between the Greek Golden Dawn and right-wing extremist protesters provides another example of a close association

\footnotetext{
${ }^{3}$ See www.zeit.de/politik/deutschland/2018-03/alternative-fuer-deutschland-pegida-kooperationsverbotgekippt
} 
between a right-wing populist party and an ideologically like-minded social movement. Yet in terms of organization, Golden Dawn is a traditional party rather than a hybrid incorporating features of a social movement, and the same applies to other populist parties on the right.

The emphasis on horizontal, informal, and networked structure relates to the demand for direct, participatory democracy that was particularly strong in the various Indignation and Occupy movements that coordinated their actions largely in the digital networks of social media and made decisions in general assemblies (Gerbaudo 2013, 2017). The left-wing populist parties that built their success on these movements, Podemos and SYRIZA, have largely retained the ideal of open and participatory democracy in spite of moving toward more vertical, representational, and leader-centered forms of organization. Podemos in particular has adopted participatory practices such as new technologies of grassroots engagement from social movements to complement more traditional forms of political engagement and action such as low-level communitarian gatherings (Kioupkiolis 2016; Gerbaudo 2017). This 'technopolitics' includes local and sectorial 'circles' of members and sympathizers that constitute a key node in the party organization as well as a permanent online 'agora', in which party members can think and collaborate in the making of common policies and ideas as well as vote on various issues. SYRIZA has not promoted an analogous participation of citizens in the party and the formulation of its policies. This may be due to its being founded as a coalition of diverse leftist groups that never questioned the traditional form of the party. Yet, together, the attempts of left-wing populists to foster networked, open, and participatory democracy in the age of social media differ from the leader-driven social media strategies favored by right-wing populist politicians, which have 
included rhetorically innovative blogs or Twitter messages of their (often charismatic) elite (Brubaker 2017).

The horizontal, open, and networked structure of left-wing social movements and - to some extent - parties allows the participating individuals to share their emotions and ideas in their communications and assemblies, both off- and online, and to constitute a collective identity as aggrieved citizens, who nevertheless are empowered by their affective solidarity and collective political agency (Gerbaudo 2017). Certainly, protests and gatherings of rightwing populists also produce solidarity through the sharing of negative emotions, in particular anger, anxiety, outrage, and indignation. However, these gatherings are far less frequent than amongst left-wing populists, they do not (yet) belong to the key cultural practices of right-wing supporters, and they rarely involve the sharing of identity threatening individual emotions, rather capitalizing on the sharing of what we surmise to be ressentiment-mediated negative emotions directed at outgroups. ${ }^{4}$

For the left, public encampments at Puerta del Sol, Syntagma Square, or Zuccotti Park provided beacons of action that offered on-site and ritualized experiences of mutual solidarity, and electrified wider communities that followed their events in live broadcasts on social media (Gerbaudo 2013). We may surmise that this sense of being part of unfolding joint action, either on site or through social media, contributed to shared experiences of joy, hope, and empowerment that helped those involved to transform their low-energy, reactive emotions such as fear, anxiety, and shame - insofar as they felt such emotions in the first

\footnotetext{
${ }^{4}$ See the Vice News coverage of the Charlottesville, VA, alt-right gathering for the exceptionality of this kind of sharing amongst the radical populist right: https://news.vice.com/en_us/article/qvzn8p/vice-news-tonightfull-episode-charlottesville-race-and-terror
} 
place - into high-energy, active emotions such as frustration, indignation, and anger

frequently reported as motives for left-wing activists' struggle against the political establishment.

In this way, the emotional dynamics of left-wing populist movements and parties resembles that of civil rights movements - black, women, gay, lesbian, etc. - where the transformation of shame and humiliation into anger and pride has been an essential element and condition of their success (e.g. Britt \& Heise 2000; Gould 2009). Along with collective agency and joint actions of protest and struggle, positive emotions of joy and hope emerge. This also includes confidence in the possibility of imminent rupture and change, all of which have been observed in the context of left-wing political movements and parties such as Podemos, SYRIZA as well as the Venezuelan Chavismo (Gerbaudo 2013; Stavrakakis \& Katsambekis 2014; Kioupkiolis 2016; Simiti 2016). These positive emotions have been less prevalent among right-wing populists. ${ }^{5}$ This is unsurprising given that their parties typically operate in ways that resemble those of traditional parties whose members and sympathizers do not act together on a regular basis even if right-wing populist parties like to characterize themselves as social movements.

\subsection{EMOTIONAL DISTANCING FROM OR EMBRACING OF SOCIAL IDENTITIES}

\footnotetext{
${ }^{5}$ There is evidence on collective pride and joy felt in the encounters of right-wing populists and extremists as well (e.g. Ahmed, 2004). However, this pride may emerge from repressed individual shame as it often shares features that Tracy and Robins (2004) have associated with hubristic individual pride, namely narcissistic selfaggrandizement and antisocial behavior toward members of outgroups. Hubristic collective pride (Sullivan, 2014) and collective narcissism (Golec de Zavala et al., 2009) have been associated with prejudice and hostility towards outgroups, the latter also with low implicit group esteem. Right-wing populist pride may then be a different kind of positive emotion than those experienced by left-wing activists.
} 
Finally, we suggest that the difference between the repression and acknowledgement of shame and other negative self-focused emotions has important implications for social identities. We argue that right-wing populism is associated with the emotional distancing from those social identities that in contemporary societies frequently evoke shame and other negative emotions (fear, powerlessness, worthlessness), whereas left-wing populists embrace and seek to support those precarious identities in spite of the negative emotions they generate.

Social identities which are linked to competitive market outcomes are particularly shameprone and therefore liable to alienation, especially for people occupying precarious positions. ${ }^{6}$ These identities include occupational identities which used to be relatively stable (and thus were building blocks of status, recognition, and honor), but have come under notable pressure over recent years (Bauman 1998; Beck 2000; Sennett 2006; Hochschild 2016). This is true for the occupational identities of low- and medium skilled blue-collar workers who have largely lost their trust in trade unions as protectors of their interests as well as for white-collar workers whose employers have faced increasing pressures to cut expenditures. Indeed, in flexible labor markets where seamless working careers are rather the exception, it makes little sense to develop strong emotional attachments to one occupational identity. Instead, social identities that do not involve competition - such as nationality, ethnicity, language, religion, and gender - become more attractive as sources of

\footnotetext{
${ }^{6}$ Theoretical support for the argument of emotional distancing from shame-prone social identities comes from sociological identity theories. Stets and Burke (2005) argue that when the self is evaluated as responsible for identity disruption, negative emotions such as shame and embarrassment ensue. People try to change the meanings of situations in which their identity is not verified in social interaction. However, if this is impossible, the theory predicts that their identity standards and identities will change.
} 
meaning, self-esteem, and efficacy. These are also identities in which solidarity and belonging with other group members can still be experienced in the framework of shared concerns, emotions, meanings, and nostalgic recollections, unlike in the context of those social identities where individuals tend to compete with everyone else.

The weakening of workers' mutual solidarity and of the power of their trade unions in conjunction with the precariousness of occupational identities therefore tends to hamper the mobilization of the traditional left. Even more, it benefits the populist right which attracts voters by repeatedly emphasizing the relevance and gratification of allegedly "natural" and "stable" social identities. These identities are discursively framed as less contingent and less demanding than identities based on a combination of effort, dedication, and luck, such as having a professional career.

Taking pride in the ascriptive aspects of identity, such as ethnicity, nationality, or gender - in general, what one already is or has - is far less demanding and complicated than taking pride in what one has achieved, for the latter kind of pride requires constant efforts with increasingly uncertain chances of success. Insofar as there is competition at the group level, individuals can identify with their fellow group members, for instance national teams in sports, who are competing in the name of the entire group. Stable social categories may become attractive as a kind of bedrock onto which one can fall back if the other, more contingently rewarding social identities fail to yield positive experiences in support of the self. This may explain the popularity of right-wing populism both among the 'losers' and some 'winners' of contemporary neoliberal capitalism. For those in disadvantaged positions, the appeal of stable social identities is obvious. But they can appeal also to those who profit 
from globalization and economic liberalization because they are aware of the precariousness of contemporary social life (Mols \& Jetten 2016).

Looking at the potential emotional distancing from social identities, we argue that the transformation of acknowledged and shared shame and humiliation into anger, resentment, and pride has important implications. In contrast to right-wing populism, left-wing populist parties have for a long time sought to politically and discursively strengthen and reinforce precarious identities. They generally advocate vindicating the right to employment, housing, social protection, health, education, the cancellation of unjust debt, and the end of austerity policies (Kioupkiolis 2016; Ivaldi et al. 2017). Relating to occupational identities in particular, they support increases in minimum wage, the unionization of workers, bans of zero-hour contracts, reduced working hours, paid family and sick leaves, paid vacation, etc. ${ }^{7}$ These policies aim at protecting and nurturing precarious occupational identities of workers, as well as other identities whose successful maintenance depends on financial resources raised from work. Insofar as voters support these policies and can stay encouraged about their realization in spite of political uncertainties, we surmise that they have less psychological incentives to find alternative identities for their sources of pride and self-esteem.

On a more general account, the rise of populist parties and movements, both right- and leftwing, can be associated with the increased relevance of identity politics. Identity politics has been the means of various traditionally disadvantaged or marginalized groups such as women, people of color, the disabled, and sexual minorities to claim for and achieve

\footnotetext{
7 e.g., http://feelthebern.org/bernie-sanders-on-workers-rights/ https://openeurope.org.uk/today/blog/podemos-economic-proposals/
} 
recognition as citizens with equal rights in contemporary democratic societies. The political left, including the populist left, has in general engaged more thoroughly and substantially in this kind identity politics than the right (e.g. Stavrakakis \& Katsambekis 2014). Emphasizing the principles of justice and equality, left-wing parties have campaigned for the recognition and esteem of various marginalized identities, such as racial, gender, and ethnic identities, seeking to transform the shame frequently associated with these identities into pride and admiration. This is likely to have contributed to the acceptance of shame-prone identities that have become fragile and precarious only over the past years, such as certain occupational identities, amongst the left.

Right-wing populism, in turn, has been seen as a backlash to identity politics and the preferential treatment of traditionally disadvantaged or marginalized groups. For instance, in Hochschild's (2016) psychological deep story of Tea Party and Trump supporters, members of these groups are identified as "line cutters" who are unfairly granted resources and benefits that others perceive as becoming unattainable or slipping away regardless of work and effort. It might be possible to blame right-wing populists for ignoring other moral grounds of fair distribution besides work, such as the principle of equal basic opportunities, and to praise left-wing populists for recognizing such grounds. However, as social scientists we are more interested in the emphasis of work as the sole criterion of distributive justice in the populist right narrative as it reveals the value of work for these people even if it has ceased to be the key to prosperity, security, and honor for them (Hochschild 2016). For this shows that the increased salience of those social identities that right-wing populists seek to protect - culture, religion, ethnicity, nationality - coincides with the precarization of other important aspects of identity that relate to work and occupation. 


\section{CONCLUSIONS}

This contribution aimed at addressing the question of why in recent years right-wing populist parties and movements have garnered considerably more support in Europe and many other countries than left-wing populist parties and movements, despite being subjected to similar crises and challenges (e.g., the European debt crisis and the migration crisis). To answer this question, we have introduced the concept of emotional opportunity structures (EOS) to the study of emotions in populism, and argued that contemporary societies have given rise to particular EOS with some cultural and regional variations which are reflected in populist narratives and strategies at exploiting these EOS. More specifically, we have identified three principal differences in the emotional dynamics of right- and leftwing political populism that we claim lie behind their differentially constructed targets of anger and resentment: a political and economic establishment deemed responsible for austerity politics (left), and political and cultural elites accused of favoring various ethnic, religious, and sexual outgroups at the expense of the neglected ingroup (right).

Firstly, right-wing resentment at outgroups may be mediated by ressentiment - the repression of negative self-focused emotions, particularly shame, and the transformation of these emotions into anger, resentment, and hate at generic others - whereas left-wing resentment may emerge from the acknowledgement and social sharing of negative selffocused emotions, which allows and supports their transformation into anger and 
indignation at particular others, but also into pride, joy, and hope similarly as in various civil rights movements.

Secondly, we proposed that differences in the organizational culture and structure of rightand left-wing political movements and parties play an important role in their dissimilar exploitation of EOS and the emotion management strategies they (can) employ. The horizontal, open, and networked structure of left-wing social movements and parties allows participants to share emotions and ideas in their communications and assemblies and to constitute a collective identity as aggrieved citizens, who are empowered by their affective solidarity and collective political agency. By contrast, right-wing populist parties share a vertical, formal, hierarchical, and representational structure with traditional parties even if they often characterize themselves as social movements. Protests of right-wing populists also produce solidarity through the sharing of negative emotions, even if protests do not belong to key cultural practices of right-wing populism. However, they rarely involve the sharing of identity threatening individual emotions, rather capitalizing on negative emotions directed at outgroups.

Thirdly, we argued that the difference between repression and acknowledgement of shame and other negative self-focused emotions has important implications for social identities. Repression associates with emotional distancing from precarious social identities tagged with negative emotions, whereas acknowledgment has no such effect but rather associates - tallying the respective discourse - with embracement and support of such identities. 
pave the way to empirically investigating our propositions. The argument outlined in this contribution suggests a number of testable hypotheses that pertain to associations between the experience of specific emotions, sociodemographic indicators, voting behavior, and participation in right- and left-wing populist parties and political or social movements. Admittedly, the more causal transformative mechanisms we suggest might be difficult to pin down, but longitudinal and/or cross-national data could prove useful in approximating the effects we assume. Also, in-depth interviews might contribute to revealing the emotional experiences that are associated with support for right- and left-wing populist parties, respectively. Finally, comparative studies may directly address some of the implied differences between support for right- and left-wing populist parties as well as differences between parties of either sort in different countries.

\section{ACKNOWLEDGEMENTS}

The authors would like to thank anonymous reviewers of this article, the editors of the Humanity \& Society special issue, as well as several commentators at Mainstreaming Populism workshop, University of Helsinki, on April 13, 2018; European Sociological Association 13th conference, Athens, on August 29 - September 1, 2017; and International Society for Research on Emotion, St. Louis, on July 25-28, 2017, for valuable comments and suggestions on the earlier versions of this article. Christian von Scheve also acknowledges the support of this research by the German Research Foundation (DFG) within the SFB 1171 'Affective Societies'. 


\section{REFERENCES}

Ahmed, Sara. 2004. “Affective Economies”. Social Text 22: 117-139.

Ahmed, Sara. 2010. The Promise of Happiness. Durham, NC: Duke University Press.

Bauman, Zygmunt. 1998. Work, Consumerism, and the New Poor. Buckingham: Open University Press.

Bauman, Zygmunt. 2001. The Individualized Society. Cambridge: Polity Press.

Beck, Ulrich. 2000. The Brave New World of Work. Cambridge: Polity Press.

Betz, Hans-Georg. 1994. Radical Right-Wing Populism in Western Europe. London: Macmillan.

Britt, Lory, and David R. Heise. 2000. "From Shame to Pride". Pp. 252-268 in Self, Identity, and Social Movements. Edited by Sheldon Stryker, Timothy J. Owens, and Robert W. White. Minneapolis: University of Minnesota Press.

Brubaker, Rogers. 2017. “Why Populism?” Theoretical Sociology 46: 357-385

Cramer, Katherine J. 2016. The Politics of Resentment. Chicago: University of Chicago Press.

della Porta, Donatella. 2015. Social Movements in Times of Austerity. Cambridge: Polity Press.

Elster, Jon. 1999. Alchemies of the Mind. Cambridge: Cambridge University Press. 
Fella, Stefano, and Carlo Ruzza. 2013. "Populism and the Fall of the Centre-Right in Italy: The End of the Berlusconi Model or a New Beginning?" Journal of Contemporary European Studies 21(1): 38-52.

Flecker, Jörg, Gudrun Hentges, and Gabrielle Balazs. 2007. “Potentials of Political Subjectivity and the Various Approaches to the Extreme Right: Findings of the Qualitative Research". Pp. 35-62 in Changing Working Life and the Appeal of the Extreme Right. Edited by Jörg Flecker. Aldershot: Ashgate.

Foucault, Michel. 2008. The Birth of Biopolitics: Lectures at the Collège de France, 1978-79. Translated by G. Burchell. New York: Palgrave Macmillan.

Furedi, Frank. 2007. Invitation to Terror. London: Continuum.

Gamson, William A., and David S. Meyer. 1996. “Framing Political Opportunity”. Pp. 275-290 in Comparative Perspectives on Social Movements. Edited by Doug McAdam, John D. McCarthy, and Mayer N. Zald. New York: Cambridge University Press.

Gerbaudo, Paulo. 2013. Tweets and the Streets. London: Pluto Press.

Gerbaudo, Paulo. 2017. The Mask and the Flag. Oxford: Oxford University Press.

Golec de Zavala, Agnieszka, Aleksandra Cichocka, Roy Eidelson, and Nuwan Jayawickreme. 2009. "Collective Narcissism and its Social Consequences". Journal of Personality and Social Psychology 97: 1074-1096.

Goodwin, Jeff. 1997. “The Libidinal Constitution of a High-Risk Social Movement: Affectual Ties and Solidarity in the Huk Rebellion, 1946 to 1954." American Sociological Review 62: 53-69. 
Gould, Deborah. 2009. Moving Politics. Berkeley, CA: University of California Press.

Guiso, Luigi, Helios Herrera, and Massimo Morelli. 2017. Demand and Supply of Populism.

CEPR Discussion Paper No. DP11871. Available at SSRN: https://ssrn.com/abstract=2924731

Hochschild, Arlie R. 2016. Strangers in the Own Land. Anger and Mourning on the American Right. New York \& London: The New Press.

Hoggett, Paul, Hen Wilkinson, and Phoebe Beedell. 2013. "Fairness and the Politics of Resentment". Journal of Social Policy 42(3): 567-585.

Ivaldi, Gilles, Maria Elisabetta Lanzoni, and Dwayne Woods. 2017. "Varieties of Populism across a Left-Right Spectrum: The Case of the Front National, the Northern League, Podemos and Five Star Movement". Swiss Political Science Review. https://doi.org/10.1111/spsr.12278

Iyengar, Shanto, Gaurav Sood, and Yphtach Lelkes. 2012. "Affect, not Ideology: A Social Identity Perspective on Polarization". Public Opinion Quarterly 76(3): 405-431.

Kinnvall, Catarina. 2013. "Trauma and the Politics of Fear: Europe at the Crossroads". Pp. 143-166 In Emotions in Politics. Edited by Nicolas Demertzis. Basingstoke: Palgrave Macmillan.

Kioupkiolis, Alexandros. 2016. “Podemos: The Ambiguous Promises of Left-Wing Populism in Contemporary Spain". Journal of Political Ideologies 21(2): 99-120.

McAdam, Doug. 1996. “Conceptual Origins, Current Problems, Future Directions”. Pp. 23-40 in Comparative Perspectives on Social Movements. Edited by Doug McAdam, John D. McCarthy, and Mayer N. Zald. Cambridge: Cambridge University Press. 
Meyer, David S. 2004. "Protest and Political Opportunities". Annual Review of Sociology 30: 125-145.

Meltzer, Bernard N. and Gil R. Musolf. 2002. "Resentment and Ressentiment". Sociological Inquiry 72: 240-255.

Miceli, Maria, and Cristiano Castelfranchi. 2015. Expectancy and Emotion. Oxford: Oxford University Press.

Mols, Frank, and Jolanda Jetten. 2016. “Explaining the Appeal of Populist Right-Wing Parties in Times of Economic Prosperity". Political Psychology 37(2): 275-292.

Mudde, Cas, and Cristóbal Rovira Kaltwasser. 2012. Populism in Europe and the Americas: Threat or Corrective for Democracy? Cambridge: Cambridge University Press.

Neckel, Sighard. 1991. Status und Scham. Frankfurt am Main: Campus.

Polletta, Francesca. 2004. "Culture Is Not Just in Your Head". Pp. 97-110 In Rethinking Social Movements. Edited by Jeff Goodwin and James M. Jasper. New York: Rowman \& Littlefield. Rackow, Katja, Jürgen Schupp, and Christian von Scheve. 2012 “Angst und Ärger. Zur Relevanz emotionaler Dimensionen sozialer Ungleichheit". Zeitschrift für Soziologie 41(5): 391-409.

Ramiro, Luis, and Raul Gomez. 2017. "Radical-Left Populism during the Great Recession: Podemos and Its Competition with the Established Radical Left". Political Studies 65(1S): $108-126$.

Ruiz-Junco, Natalia. 2013. “Feeling Social Movements: Theoretical Contributions to Social Movement Research on Emotions". Sociology Compass 7(1): 45-54. 
Salmela, Mikko, and Christian von Scheve. 2017. "Emotional Roots of Right-Wing Political Populism". Social Science Information 56(4): 567-595.

Scheff, Thomas J. 1994. Bloody Revenge. Lincoln: Authors Guild.

Scheler, Max. 1994[1915]. Ressentiment. Translated by Louis A. Coser, with an introduction by Manfred S. Frings. Milwaukee, WI: Marquette University Press.

Sennett, Richard. 2006. The Culture of the New Capitalism. New Haven \& London: Yale University Press.

Simiti, Marilena. 2016. "Rage and Protest: The Case of the Greek Indignant Movement". Contention: The Multidisciplinary Journal of Social Protest 3(2): 33-50.

Stavrakakis, Yannis, and Giorgos Katsambekis. 2014. "Left-wing Populism in the European Periphery: The Case of SYRIZA". Journal of Political Ideologies 19(2): 119-142.

Stets, Jan E., and Peter J. Burke 2005. "New Directions in Identity Control Theory". Advances in Group Processes 21: 51-76.

Stodulka, Thomas. 2017. Coming of Age on the Streets of Java. Bielefeld: transcript.

Strawson, Peter. 1974. Freedom and Resentment and Other Essays. London: Methuen \& Co Ltd.

Sullivan, Gavin B. 2014. "Collective Pride and Collective Arrogance in Organizations". Pp. 8092 in Understanding Collective Pride and Group Identity. Edited by Gavin B. Sullivan. London: Routledge.

Tilly, Charles. 1978. From Mobilization to Revolution. Reading, MA: Addison-Wesley. 
Tracy, Jessica L., and Richard W. Robins. 2004. "Putting the Self into Self-Conscious

Emotions: A Theoretical Model". Psychological Inquiry 15(2): 103-125.

Turner, Jonathan H. 2007. "Self, Emotions, and Extreme Violence: Extending Symbolic Interactionist Theorizing". Symbolic Interaction 30(4): 501-530.

Wacquant, Loic. 2008. Urban Outcasts. Cambridge: Polity.

Whittier, Nancy. 2001. "Emotional Strategies: The Collective Reconstruction and Display of Oppositional Emotions in the Movement Against Child Sexual Abuse". Pp. 233-250 in Passionate Politics. Edited by Jeff Goodwin, James M. Jasper, and Francesca Polletta. Chicago: University of Chicago Press.

Xenakis, Sappho, and Leonidas Cheliotis. 2014. "Anger Management and the Politics of Crime in the Greek Crisis". Pp. 142-159 in The Politics of Extreme Austerity: Greece in the Eurozone Crisis. Edited by Georgios Karyotis and Roman Geronimos. London: Palgrave Macmillan.

Joint reflexive statement

Mikko Salmela works in the areas of empirically informed philosophy of emotions and philosophical psychology, and Christian von Scheve in the fields of the sociology of emotion, culture, and stratification. Their interest in political populism is motivated by recent shifts in the political landscapes in Europe and the United States that have led to an increasing support for especially right-wing populist parties amongst the electorate. In an effort to better understand these shifts, Salmela and von Scheve have extended their years-long 
collaboration on the social dimensions of emotions to develop theoretical models of, first, right-wing populist, and, later on, also left-wing populist support that account for both, macro-level structural changes and micro-level psychological factors. 